\title{
Work Breakdown Structure and Plant/Equipment Designation System Numbering Scheme for the High Temperature Gas- Cooled Reactor (HTGR) Component Test Capability (CTC)
}

Jeffrey D. Bryan

September 2009
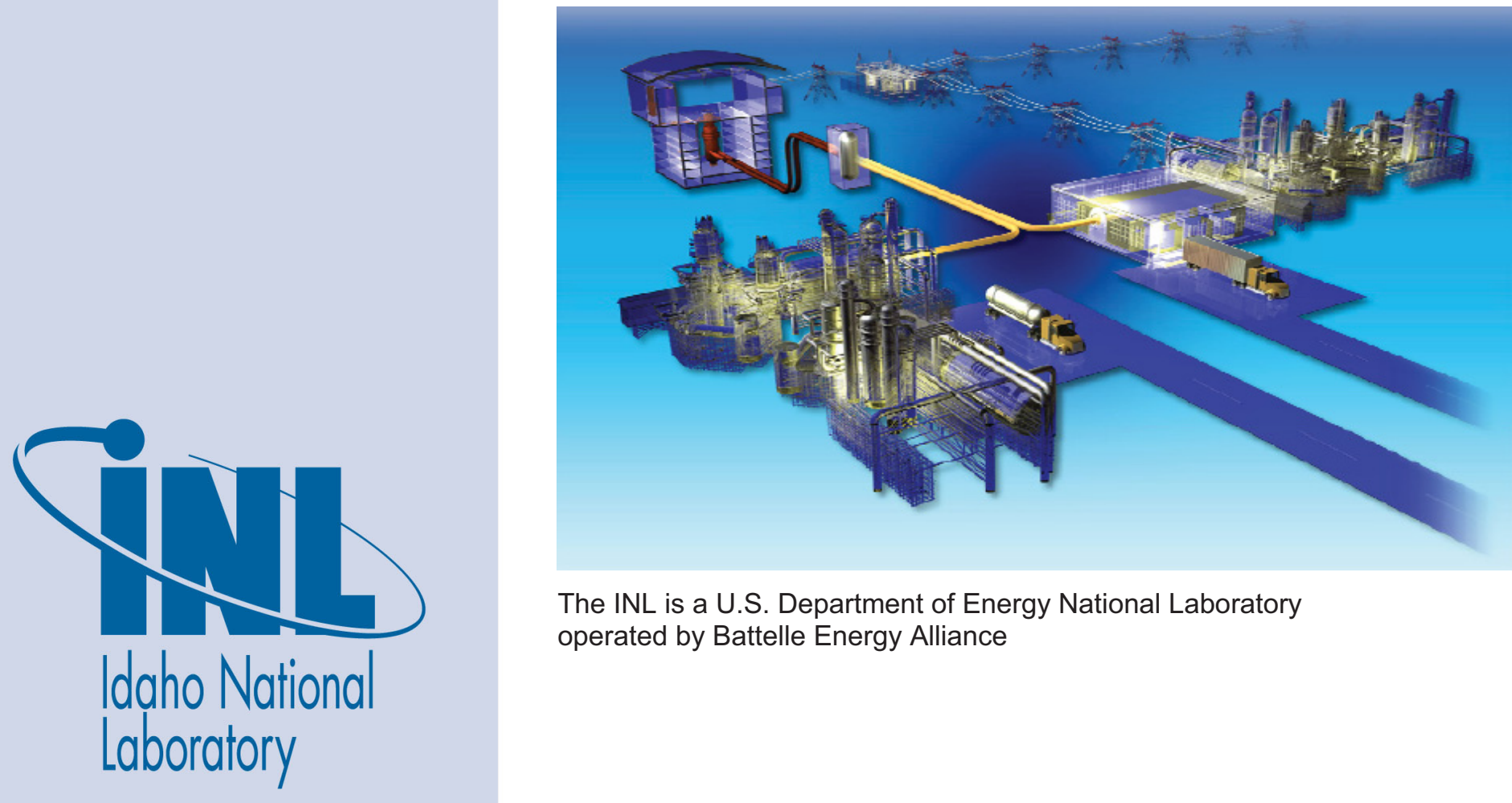

The INL is a U.S. Department of Energy National Laboratory operated by Battelle Energy Alliance 


\title{
Work Breakdown Structure and Plant/Equipment Designation System Numbering Scheme for the High Temperature Gas-Cooled Reactor (HTGR) Component Test Capability (CTC)
}

\author{
Jeffrey D. Bryan
}

September 2009

\author{
Idaho National Laboratory \\ Next Generation Nuclear Plant (NGNP) Project \\ Idaho Falls, Idaho 83415 \\ http://www.inl.gov
}

Prepared for the

U.S. Department of Energy

Office of Science

Under DOE Idaho Operations Office

Contract DE-AC07-05ID14517 


\section{DISCLAIMER}

This information was prepared as an account of work sponsored by an agency of the U.S. Government. Neither the U.S. Government nor any agency thereof, nor any of their employees, makes any warranty, expressed or implied, or assumes any legal liability or responsibility for the accuracy, completeness, or usefulness, of any information, apparatus, product, or process disclosed, or represents that its use would not infringe privately owned rights. References herein to any specific commercial product, process, or service by trade name, trade mark, manufacturer, or otherwise, does not necessarily constitute or imply its endorsement, recommendation, or favoring by the U.S. Government or any agency thereof. The views and opinions of authors expressed herein do not necessarily state or reflect those of the U.S. Government or any agency thereof. 
INL/EXT-12-25847 
INL/EXT-12-25847

Next Generation Nuclear Plant (NGNP) Project

WHITE PAPER

Work Breakdown Structure and Plant/Equipment Designation System Numbering Scheme for the High Temperature Gas-Cooled Reactor (HTGR) Component Test Capability (CTC)

September 2009

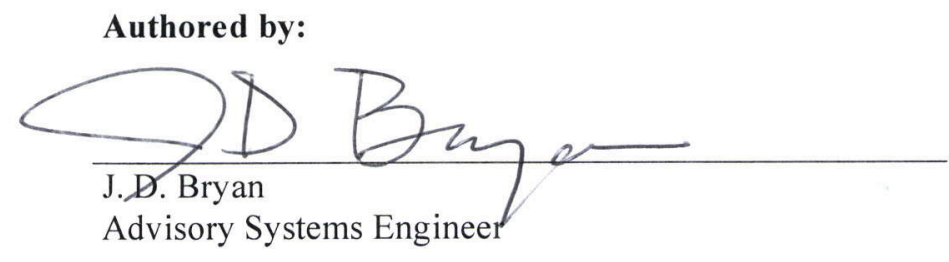

$$
9 / 28 / 2009
$$


INL/EXT-12-25847 


\section{CONTENTS}

ACRONYMS viii

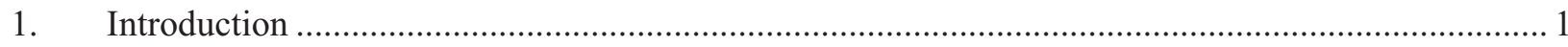

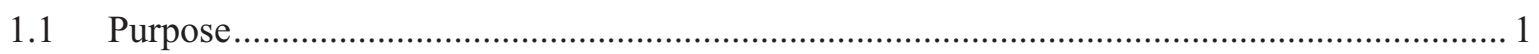

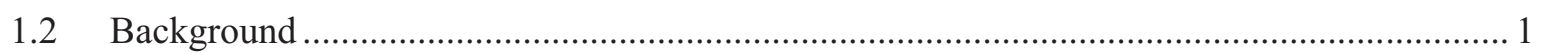

1.3 Laboratory and Project Work Breakdown Structure Integration ........................................ 1

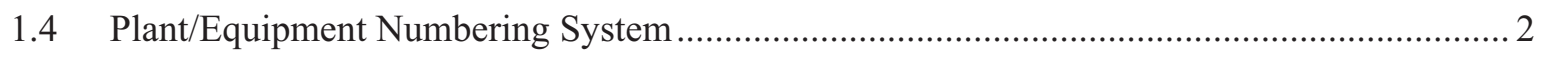

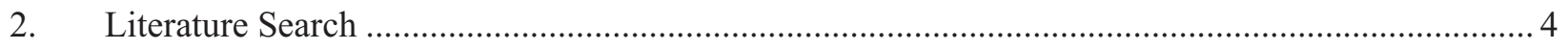

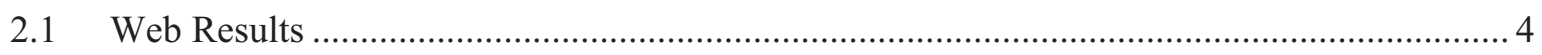

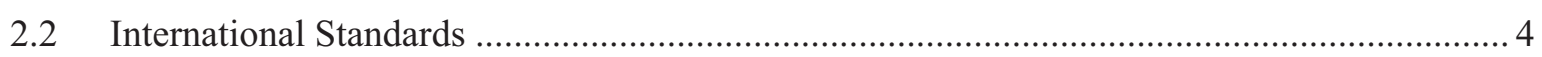

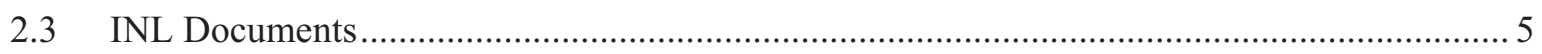

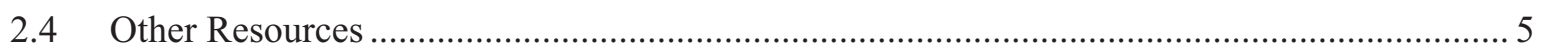

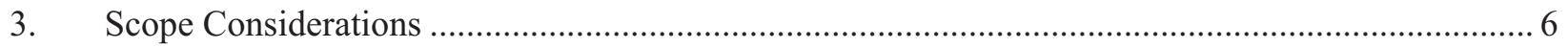

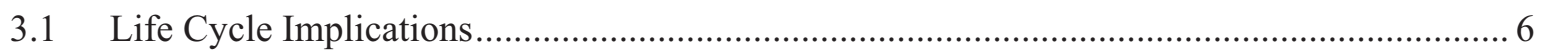

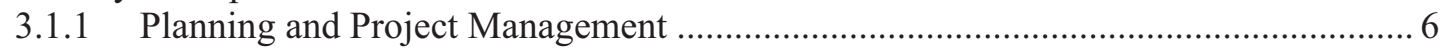

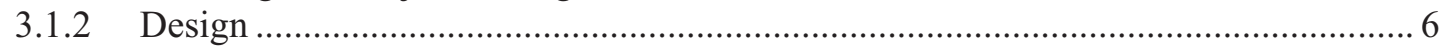

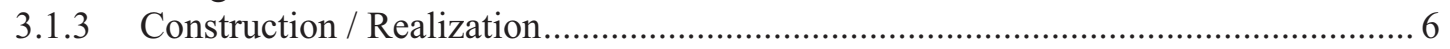

3.1.4 Project Closeout/Turnover and Commissioning ................................................. 6

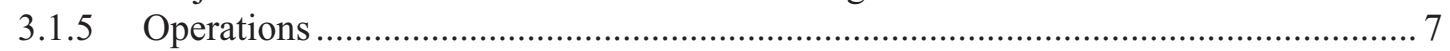

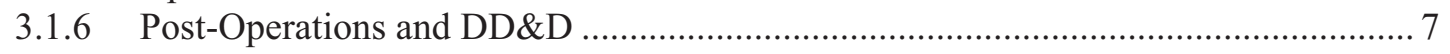

3.2 Possible INL Business Process Interfaces................................................................... 8

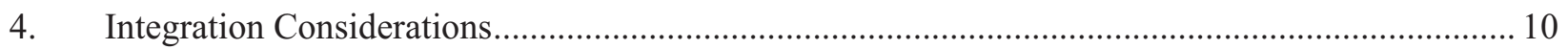

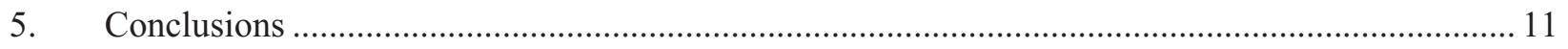

\section{FIGURES}

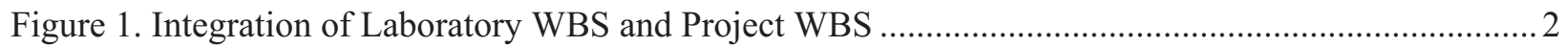

Figure 2. Reference Designation System for Power Plants (RDS-PP) showing relationships between the function, product, and location aspects for an example object................................ 3

Figure 3. Potential Interfaces for the Integrated WBS and Plant Numbering System (or RDS). ............... 8 
INL/EXT-12-25847 


\section{ACRONYMS}

BEA Battelle Energy Alliance, LLC

BIM Building Information Modeling

CMMS Computerized Maintenance Management System

CTC Component Test Capability

DD\&D Deactivation, Decommissioning, and Dismantlement

DOE Department of Energy

DOE-ID Department of Energy, Idaho Operations Office

F\&ORs Functional and Operational Requirements

HTGR High Temperature Gas-cooled Reactor

INL Idaho National Laboratory

IPS Integrated Project System

LWP Laboratory-wide Procedure

NGNP Next Generation Nuclear Plant

PDMS Plant Data Management System

PNS Plant/equipment Numbering System (generic)

PLN Plan

RDS Reference Designation System

RDS-PP Reference Designation System for Power Plants

SSCs structures, systems, and components

TFRs Technical and Functional Requirements 
INL/EXT-12-25847 
INL/EXT-12-25847

\section{Work Breakdown Structure and Plant/Equipment Designation System Numbering Scheme for the High Temperature Gas-Cooled Reactor (HTGR) Component Test Capability (CTC)}

\section{Introduction}

\subsection{Purpose}

This white paper investigates the potential integration of the CTC work breakdown structure numbering scheme with a plant/equipment numbering system (PNS), or alternatively referred to in industry as a reference designation system (RDS). Ideally, the goal of such integration would be a single, common referencing system for the life cycle of the CTC that supports all the various processes (e.g., information, execution, and control) that necessitate plant and equipment numbers be assigned. This white paper focuses on discovering the full scope of Idaho National Laboratory (INL) processes to which this goal might be applied as well as the factors likely to affect decisions about implementation. Later, a procedure for assigning these numbers will be developed using this white paper as a starting point and that reflects the resolved scope and outcome of associated decisions.

\subsection{Background}

The need to classify and uniquely reference systems, equipment, and components within a plant arise from a multitude of sources - from design control during initial system design, to configuration management during construction/modifications, to system monitoring and control during operations, to waste disposition during deactivation and decommissioning to name only a few. A common PNS, implemented across all life cycle phases, would provide an effective backbone for quick access to data and documentation necessary to efficiently design, construct, manage, operate, maintain, and retire the CTC. This includes data acquisition for as well as monitoring and control of, as applicable, NGNP critical structures, systems and components (SSCs) undergoing technology development testing within the CTC. Such a backbone would support the development of quality assured services and administration of plant SSCs while eliminating the need for redundant data entry and for managing cross-walks necessitated by the use of multiple object referencing systems.

\subsection{Laboratory and Project Work Breakdown Structure Integration}

PLN-7305, "Project Management System Document" states that the work breakdown structure (WBS) is a hierarchical grouping of project elements that organize and define the work scope of a project. The WBS is a project tool that forms the basis for planning and scheduling work, budgeting, and reporting.

After the project is authorized, the project WBS becomes the primary tool used to ensure integrated cost and schedule control. The project WBS organizes the scope baseline and provides the hierarchical structure for cost and schedule baseline development. The WBS is maintained in the Integrated Project System (IPS) database (i.e., IPS2000) and is maintained through the project life cycle. The WBS dictionary may reside in the IPS2000 database or in a stand alone file in the shared project file. This WBS dictionary defines and describes elements of work in the project. The project WBS levels establish the WBS coding structure used for collection of cost and schedule information. 
The LWBS allows for collection of cost and schedule information at different levels within the company organization structure. The LWBS levels are defined as follows:

- Level 1 represents the INL

- Level 2 represents the Business Element (Associate Laboratory Director [ALD] or Service Director)

- Levels 3 through 7 are available for projects to use to organize the scope baseline based on the complexity of the project.

Laboratory WBS

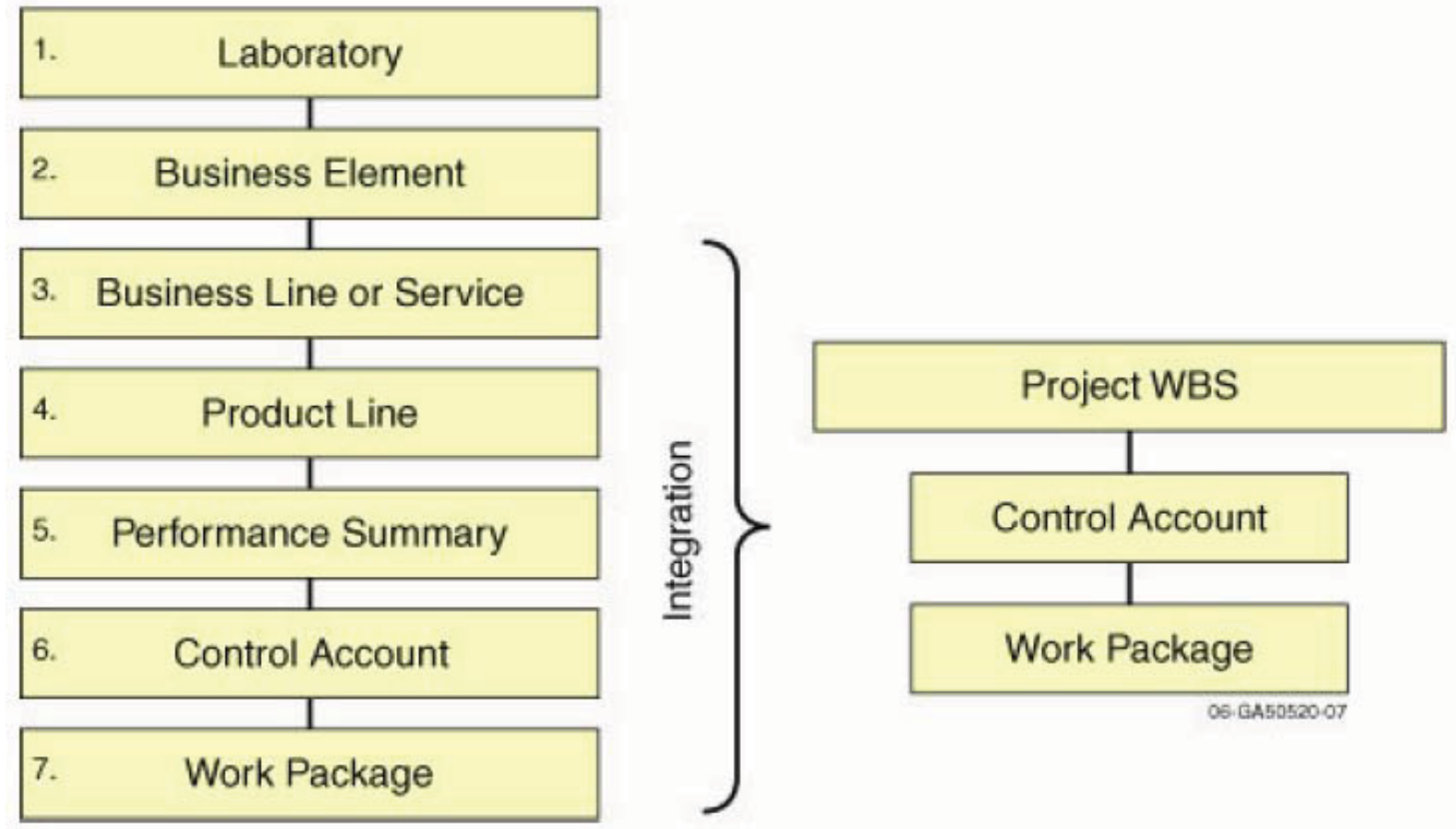

Figure 1. Integration of Laboratory WBS and Project WBS

\subsection{Plant/Equipment Numbering System}

The PNS, or RDS, is a means to uniquely classify and identify parts of an industrial plant. IEC 61346-1:1996 specifies that "the reference designation identifies objects for the purpose of correlating information about an object among different kinds of documents and the products implementing the system." The designation system answers the questions: What does the object do? How is the object constructed? Where is the object located? It does so through the use of "aspects" which are discussed below.

Historically, facilities and SSCs located at the Idaho National Laboratory have been numbered (assigned a reference designation) but the methods for doing so have changed over the years and have not been consistent from site area to site area. Also, a common numbering system has not been used to uniquely identify these objects across multiple purposes such as key drawing/document control, configuration management, equipment/process control, maintenance management, or field identification. 
Today, international standards exist for establishing reference designation systems for industrial sites and plants. These designations are implemented during planning and design and used throughout construction, operations, maintenance, and retirement. Figure 2, below, illustrates the structure of the Reference Designation System for Power Plants (RDS-PP) with the reference designation portion expanded to show the "aspects" used to uniquely identify the object. The RDS-PP is the replacement system for the KKS and what has been evaluated for purposes of this white paper.

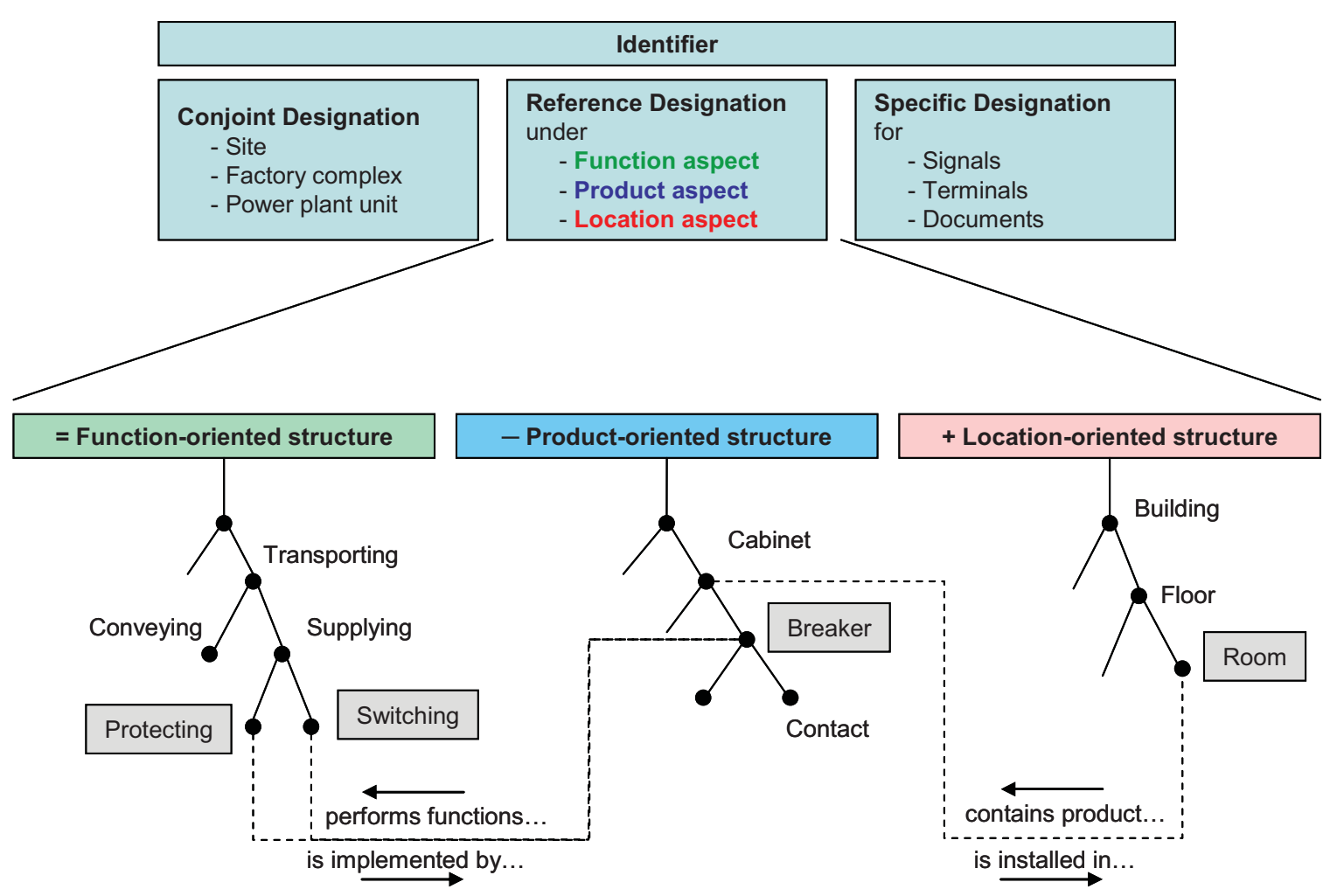

Figure 2. Reference Designation System for Power Plants (RDS-PP) showing relationships between the function, product, and location aspects for an example object.

It is anticipated that the NGNP prototype and future commercial units will also use reference designations for objects (i.e., facilities, systems, subsystems, and components). Thus, critical SSCs undergoing development testing within the CTC are also expected to carry a similar reference designation. The CTC plant/equipment numbering system should be consistent with, or at least accommodate, the NGNP RDS for the purpose of test article monitoring, control, data acquisition, and records management. 


\section{Literature Search}

\subsection{Web Results}

The following web documents were obtained and reviewed in support of the development of this white paper:

"RDS-PP - Transition from the KKS to an international standard," Dipl.-Ing. Harry Konigstein (Steag-SaarEnergie, Saarbrucken), Ing. grad. Heinz Muller (Siemens Power Generation, Erlangen), Dipl.-Ing. Jorg Kaiser (VGB-office, Essen).

"Taxonomy for Industrial Data Base to Improve Operations Management Information System," Shamsuddin Ahmed, UAE University, CBE, POB\#17555, Al Ain, UAE and Edith Cowan University, Australia.

"Plant Numbering System," (draft specification), Innovatic, Boegebakken 3, Gjessoe, DK-8600 Silkeborg, Denmark.

"KKS Power Plant Classification System," Wikipedia.

\subsection{International Standards}

The following international standards were obtained and reviewed in support of the development of this white paper:

- ISO/TS 16952-1:2006 Technical product documentation - Reference designation system Part 1: General application rules

- ISO/TS 16952-10:2008 Technical product documentation - Reference designation system Part 10: Power plants

- IEC/PAS 62400:2005 Structuring principles for technical products and technical product documentation - Letter codes - Main classes and subclasses of objects according to their purpose and task

- IEC 61346-1:1996 Industrial systems, installations and equipment and industrial products Structuring principles and reference designations - Part 1: Basic rules

- IEC 61346-2:2000 Industrial systems, installations and equipment and industrial products Structuring principles and reference designations - Part 2: Classification of objects and codes for classes

- IEC 61175:2005 Industrial systems, installations and equipment and industrial products Designation of signals

- IEC 61666:1997 Industrial systems, installations and equipment and industrial products Identification of terminals within a system

- IEC 61355-1:2008 Classification and designation of documents for plants, systems and equipment - Part 1: Rules and classification tables

In addition, VGB Guidebook B101e, "Reference Designation System for Power Plants RDS-PP Letter Codes for Power Plant Systems (System Key)" was ordered but was not received as of the drafting of this white paper. 


\subsection{INL Documents}

MCP-6402, “Master Equipment List and Maintenance History,” March 29, 2007.

LST-60, "List of Equipment Hierarchy Standard,” June 3, 2008.

LST-215, “Area Location Index Code List,” August 31, 2006.

LST-216, “Drawing Type Index Code List,” August 31, 2006.

LST-217, “Class of Work Index Code List,” August 31, 2006.

LST-218, “Drawing Originator Index Code List,” August 29, 2006.

PLN-7305, "Project Management System Document," January 23, 2007.

\subsection{Other Resources}

“SSC Coding System for EPR Design Certification Project," Procedure \#51-5064357-002, AREVA NP Inc.

Chapter 5 - Project Scope Management, "A Guide to the Project Management Body of Knowledge," Third Edition, 2004. 


\section{Scope Considerations}

The following subsections discuss the scope of Idaho National Laboratory (INL) processes to which the goal of having a single, common PNS for the CTC might be applied.

\subsection{Life Cycle Implications}

The following life cycle phases for the CTC were considered to help identify INL data and documentation products that might contribute to an object's data and documentation base and, thus, accessed through the envisioned unique reference designation for that object.

\subsubsection{Planning and Project Management}

Planning for the CTC will result in the development of a WBS for describing and controlling work elements relative to scope, schedule, and budget. The WBS can be maintained in the IPS2000 system (levels 1 to 7 only) or in a standalone file.

\subsubsection{Design}

Design of the CTC will result in various design process input and output documentation including, but not limited to:

- Functional and Operational Requirements (F\&ORs) / Technical and Functional Requirements (TFRs)

- Engineering analyses (e.g., EDFs)

- Construction and fabrication drawings

- Specifications

- Vendor testing and/or inspection plans

\subsubsection{Construction / Realization}

Realization of the CTC will result in various documentation products including, but not limited to:

- Environmental permits

- Operating procedures (draft)

- System operating (SO) test plans

- Acquisition (actual) cost

- As-built drawings

- Vendor data

- Vendor testing and/or inspection reports

\subsubsection{Project Closeout/Turnover and Commissioning}

Turnover of the CTC will result in documentation products including, but not limited to:

- Operating procedures (verified)

- SO test reports

- Turnover/acceptance reports 


\subsubsection{Operations}

In addition to the real time process control activities (e.g., SCADA) necessary to operate the CTC (plant portion), documentation products such as the following will be produced and which will need to be associated with specific CTC objects:

- Facility monitoring/inspection logs

- Environmental permit compliance/monitoring reports

- Instrumentation (fixed) calibration plans, work orders, and history/reports

- Facility (structure) maintenance inspection plans and reports

- Equipment maintenance (corrective, preventive, and predictive) plans, work orders, and history/reports

- Facility modification packages

- Inventory management and tracking documents

In addition to the real time process control activities (e.g., SCADA) necessary to conduct technology development testing on NGNP critical SSCs, CTC testing operations will require or result in documentation products such as the following which will need to be associated with specific components being tested:

- Component test plans

- Component monitoring/inspection logs

- Instrumentation (test) calibration reports

- Component test/inspection data and reports

- Component qualification reports

- other?

\subsubsection{Post-Operations and DD\&D}

Post-operations and deactivation, decommissioning, and dismantlement of the $\mathrm{CTC}$ will require or result in documentation products such as:

- Shutdown plans and configurations

- Waste determinations

- Disposal records 


\subsection{Possible INL Business Process Interfaces}

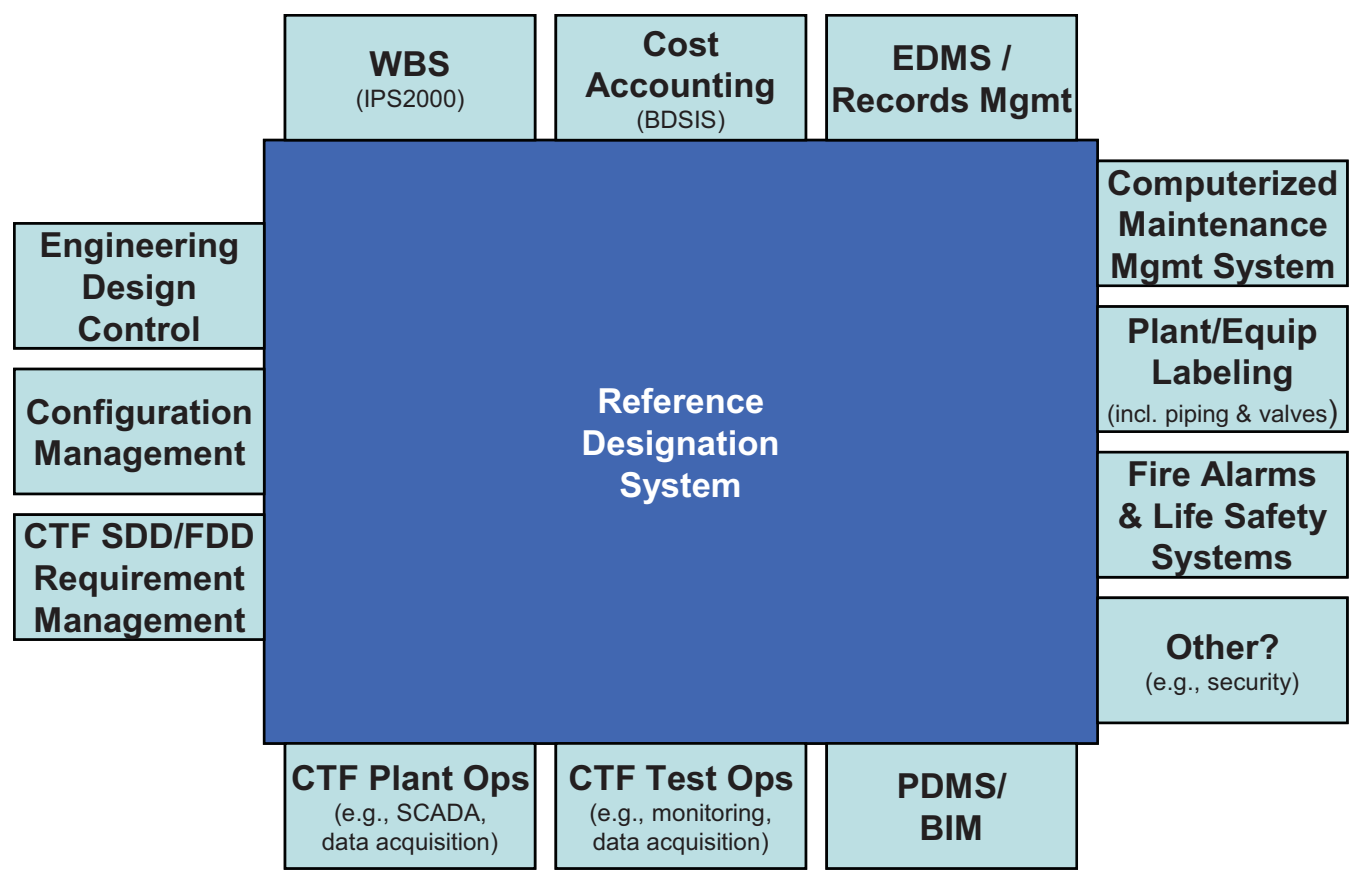

Figure 3. Potential Interfaces for the Integrated WBS and Plant Numbering System (or RDS).

After consideration of the CTC life cycle phases in Section 3.1 above, the following list of INL business processes have been compiled (see Figure 3) based on the potential for an interface with the integrated CTC WBS/RDS as envisioned (e.g., RDS-PP):

- INL Project Management System (e.g., IPS2000) - relative to the ability to accept, store, and report on work elements (including scope, budget, schedule information) as they relate to a hierarchy of objects defined for the CTC.

- INL Engineering Design Control (LWP-10400) - relative to associating new engineering designs and analyses for SSCs (or for modifications of existing SSCs) to the objects which they pertain.

- INL Drawing Requirements Standard (STD-10011) - drawing index code assignment, class of work code assignment, etc., relative to the objects which they pertain.

- INL Electronic Document Management System (EDMS) - managing controlled drawings and documents with appropriate association to the objects which they pertain.

- INL Records Management - managing records in accordance with applicable requirements and within context to the objects which they pertain.

- INL Maintenance Management Program (PRD-6000) - relies on a hierarchy standard defined in LST-60 to identify objects to be entered into the Computerized Maintenance Management System (CMMS). The CMMS contains a master equipment list, maintenance plans, work orders, and history for tracked objects.

- INL Cost Accounting - as it pertains to tracking the cost of performing WBS work elements and for capturing CTC equipment operating costs and NGNP critical SSC technology development testing costs. 
- INL Configuration Management Program (PDD-10502) - as it pertains to the management of information in Asset Suite for configuration managed items (objects). Asset Suite currently uses a 6-digit number to uniquely identify configuration items (objects) at a system-level only. It could be made to include equipment and component levels as well.

Other potential INL interfaces (not directly related to business processes):

- Requirements Management - This interface is basically a "no-impact" for integration. Unique requirement numbers are a best management practice and can easily be imbedded into requirements documents (e.g., in tables or at the end of the requirement text) and/or associated databases (e.g., as an additional requirement attribute). The unique number used could be that assigned by the integrated WBS/PNS procedure with an additional numerical sequence number to allow multiple requirements to be written for a single object.

- Plant Data Management System (PDMS) / Building Information Modeling (BIM) - References to PDMS/BIM do not appear in typical INL documents on EDMS. From the CTC Conceptual Design Work Plan this appears to be a system for accessing design data through a 3D model of the CTC and as interfaced with various databases and information systems. In this static context, or in a broader context like that discussed on the internet (e.g., adaptive building status, monitoring, and control), the use of an integrated PNS (or relevant portion thereof) would seem feasible and desirable.

- Equipment Labeling (in the field) for Operations as well as Safety/Emergency Response - While it is necessary to label pipes with "plain language" labels as to what is being conveyed (e.g., argon, plant air, potable water) for emergency response purposes, field labeling using the integrated PNS (or relevant portion thereof) would be feasible and desirable. As for interfaces with INL fire alarms and other life safety systems, there may be constraints on how alarm initiating devices are designated as well as the format of the signal. 


\section{Integration Considerations}

Attachment 1 illustrates one possible integration of the Lab and Project WBS with the RDS-PP assuming that all reference designation aspects (i.e., conjoint, function, product, location, and specific) are required to uniquely identify the full set objects (including associated signals, terminals, and documents) within the CTC to be designed and implemented. As shown, a total of 31 WBS levels would be required to fully capture the integrated object designation. In the implementation shown, each level is assigned a specific role in communicating the object's unique identifier. The exception to this rule is for the "Specific" aspect which is discussed in Con \#4 below.

Pros:

1. A standard reference designation system can be used for the entire life-cycle of the CTC and its associated systems and subsystems. This backbone facilitates access to the full range of information, data, and documentation associated with the referenced object.

Cons:

1. Lengthy number may be hard for users to decipher and also prone to transcription errors.

2. INL processes and systems would require modification to use the integrated number. The 31 levels may be difficult or infeasible to implement in such systems due to the data structure and multiple decimal points/periods.

3. Hierarchical structure is not maintained in a pure sense throughout the integrated number as within a typical WBS. Specifically, the RDS-PP is actually comprised of several hierarchical trees (i.e., "is accomplished by/contributes to", "includes/is included in", and "houses/is housed in"). As the RDS-PP number transitions from one aspect to another (e.g., Function aspect to the Product aspect, or from the Product aspect to the Location aspect) the associated relationships typically reflect allocations (or other relationships) as opposed to a continuation of the same tree.

4. The RDS-PP relies on special character prefixes (e.g., “\#”, “=”, “-”, “+”, “\&”, “;”, and ":”) to communicate what type of number is to follow. This prefix often changes the context and, therefore, interpretation of a letter in the same character position. Other than for the Specific aspect, it may be feasible to assume the prefix for a given segment of the integrated number (e.g., "Function" for integrated number levels 8 through 13). As integrated in Figure 2, the Specific aspect reuses the same set of elements and, therefore, requires the use of a level (\#26) as a flag to indicate which Specific aspect case is intended for use. Normally these prefixes allow the RDS-PP number to contain only the necessary "aspect" pieces of the unique identifier and, thus, are typically much shorter than in this implementation example. Unused WBS levels would need to be coded with " 00 ", or some other flag, that would immediately be recognized as a non-used level. 


\section{Conclusions}

It seems unlikely that many or all of the INL processes that might contribute to an object's information base (i.e., through the use of an integrated WBS and PNS) would be changed in such a way to be based on this kind of integrated reference designation scheme. This is especially true for processes that are supported by information management systems (e.g., IPS2000, Asset Suite) particularly those that are commercial-off-the-shelf and not readily customizable. Given this obstacle, a means of embedding the reference designation (e.g., adding a data field for storing it or placing the number in a searchable text field) would seem like the next plausible alternative.

Thus, the requirement that the integrated reference designation conform to the 2 character WBS structure should be re-evaluated relative to the conclusion reached above as well as the overall length and complexity that this creates for the object's designation. If an embedded number or additional field can be implemented to facilitate the cross-walking of an object's data from various sources, the embedded number would not necessarily need to be constrained to this format, particularly in light of the current IPS2000 limit to 7 WBS levels.

The use of encoded reference designations in control systems that allow monitoring and control of CTC infrastructure systems, test loops, and components being tested are not likely to be affected by limitations on the INL information systems ultimately included for integration. The CTC is new implementation and the RDS employed can be largely independent of INL processes. 


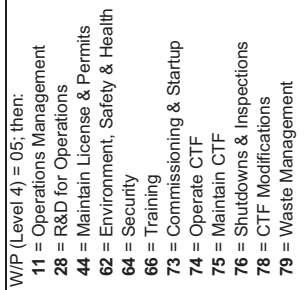

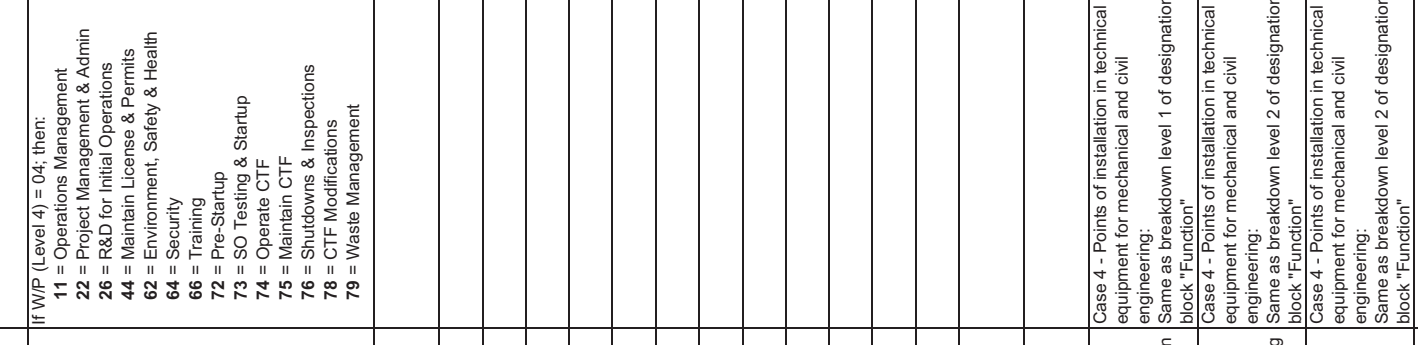

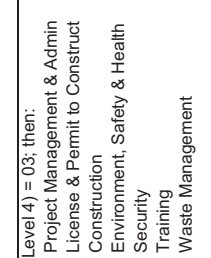

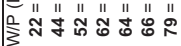

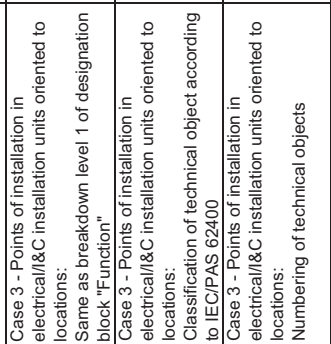

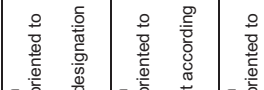

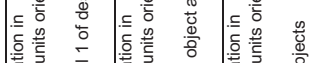

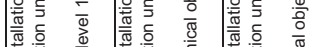

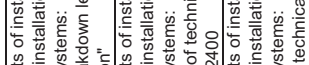

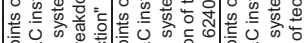

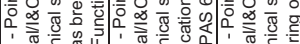

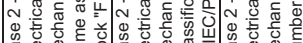

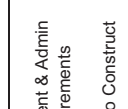

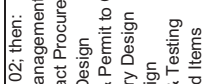

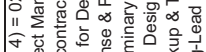

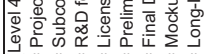

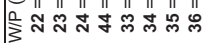

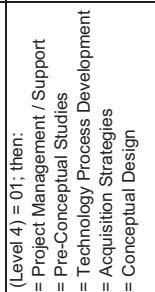

年
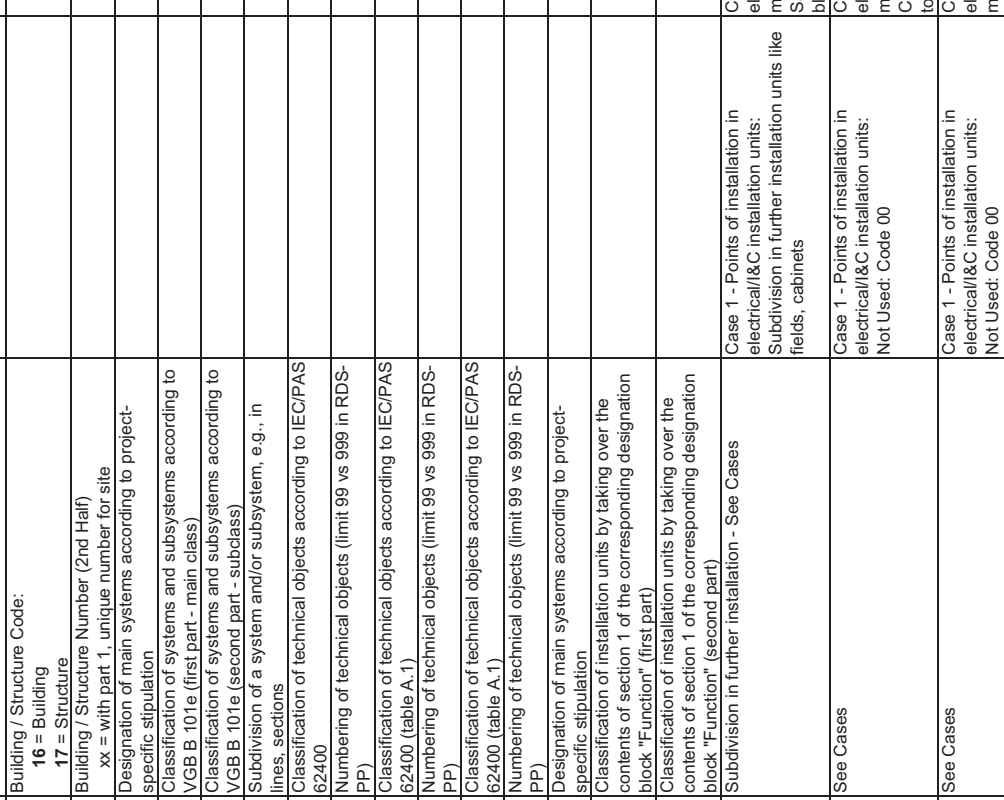

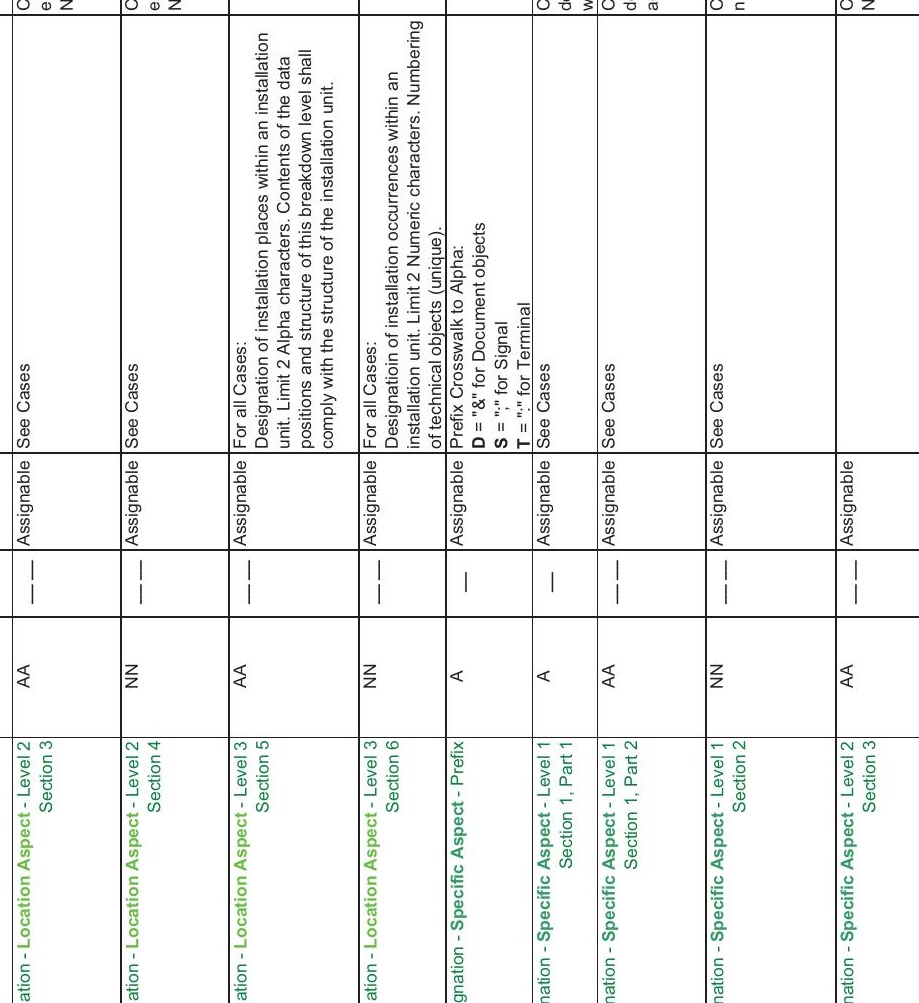

